\title{
RELEVANSI, EFEKTIVITAS DAN SUSTAINABILITAS MODEL PEMBERDAYAAN PARAJI DAN KOKOLOT DALAM UPAYA MENINGKATKAN PERSALINAN DI FASILITAS KESEHATAN
}

\author{
Relevances, Effectiveness, and Sustainability of Paraji and \\ Kokolot Empowerment Model in Efforts to Increase Delivery \\ in Health Care Facilities
}

\author{
Sri Handayani, Suharmiati, Karlina, Yurika Fauzia Wardhani \\ Puslitbang Humaniora dan Manajemen Kesehatan \\ Balitbangkes; Kementerian Kesehatan \\ Naskah masuk: 25 Juni 2020 Perbaikan: 29 November 2020 Layak terbit: 1 Februari 2021 \\ https://doi.org/10.22435/hsr.v24i1.3406
}

\begin{abstract}
ABSTRAK
Pada tahun 2017 dan 2018 Puslitbang Humaniora dan Manajemen Kesehatan melaksanakan riset intervensi kesehatan di Desa Tugu dan Desa Rancapinang, Kecamatan Cimanggu, Kabupaten Pandeglang. Riset ini dilatarbelakangi oleh masalah kesehatan ibu dan anak yang masih dialami oleh Kabupaten Pandeglang. Riset intervensi dilakukan dengan metode pemberdayaan masyarakat di mana paraji dan kokolot sebagai agen perubahan untuk meningkatkan persalinan di fasilitas kesehatan. Riset ini menggunakan pendekatan kualitatif dengan metode participatory action research (PAR). Metode pengumpulan data yang digunakan adalah wawancara mendalam, diskusi kelompok terarah dan observasi. Model pemberdayaan paraji dan kokolot dalam upaya meningkatkan persalinan di fasilitas kesehatan cukup relevan diimplementasikan karena sesuai dengan permasalahan masih adanya ibu hamil yang melahirkan di rumah. Dari segi efektivitas model ini lebih efektif dilaksanakan di Desa Tugu dibandingkan di Desa Rancapinang karena karakteristik wilayah dan masyarakat kedua desa berbeda. Sustainabilitas model ini dipertanyakan karena belum terintegrasi dengan sistem pelayanan kesehatan setempat. Sebagai saran, perlu adanya modifikasi dalam model intervensi ini yang disesuaikan dengan karakteristik sosial dan budaya masyarakat setempat. Untuk meningkatkan efektivitas model ini memerlukan kemitraan yang kuat antara paraji dan kokolot sebagai agen perubahan dengan bidan desa dan pendamping lokal. Model ini juga harus terintegrasi dengan sistem kesehatan lokal sehingga sustainabilitas dapat tercapai.
\end{abstract}

Kata Kunci: Persalinan, fasilitas kesehatan, pemberdayaan

\section{ABSTRACT}

In 2017 and 2018 the Center for Humanities and Health Management conducted health interventions research in Tugu and Rancapinang Village, Cimanggu District, Pandeglang Regency. This research is motivated by the maternal and child health problems that are still experienced in Pandeglang Regency. Intervention research was carried out using a community empowerment method where paraji and kokolot as agents of change to improve childbirth in health facilities. This research uses a qualitative approach with a participatory action research (PAR) method. Data collection methods have used in-depth interviews, focus group discussions, and observations. Paraji and kokolot empowerment model to increase childbirth in health facilities are quite relevant to be implemented because it is following the problem of the presence of pregnant women giving birth at home. In terms of effectiveness, this model is more effectively implemented in Tugu village than in Rancapinang Village because the characteristics of the area and the people of the two villages are

Korespondensi:

Sri Handayani

Puslitbang Humaniora dan Manajemen Kesehatan, Balitbangkes; Kementerian Kesehatan

E-mail : aniverret@gmail.com 
different. The sustainability of this model is questionable because it is not yet integrated with the local health service system. As a suggestion, modifying this model according to the social and cultural characteristics of the local community is necessary. Increasing effectiveness in this model is needed to have a strong partnership between paraji, kokolot as agents of change, village midwives, and local facilitators. This model must also be integrated with the local health service system so that sustainability can be realized

Keywords: Delivery, Health Facility, Empowerment

\section{PENDAHULUAN}

Masalah kesehatan ibu dan anak masih menjadi masalah kesehatan utama yang dihadapi oleh Indonesia. Data Survei Penduduk Antar Sensus (SUPAS) tahun 2015 menunjukkan Angka Kematian Ibu (AKI) dan Angka Kematian Bayi (AKB) masih cukup tinggi yaitu 305/100.000 kelahiran hidup (AKI) dan 22,23/1000 kelahiran hidup (AKB) (Pusdatin Kemenkes, 2018). Salah satu penyebab tingginya AKI dan AKB adalah masih adanya persalinan yang dilakukan di rumah bukan di fasilitas kesehatan. Data SDKI 2017 menunjukkan sebanyak $74 \%$ persalinan di Indonesia sudah dilaksanakan di fasilitas pelayanan kesehatan tetapi masih ada $21 \%$ persalinan yang dilaksanakan di rumah. Persalinan dengan ditolong oleh tenaga kesehatan sudah dilakukan sebanyak $91 \%$ dan masih ada persalinan yang ditolong oleh dukun sebesar $7 \%$ (Badan Pusat Statistik, 2017).

Pemerintah telah melakukan berbagai upaya untuk mengatasi masalah kesehatan ibu dan anak. Kebijakan yang telah dilakukan pemerintah antara lain adalah program antenatal dan postnatal care untuk ibu hamil, ketentuan tenaga kesehatan profesional sebagai penolong persalinan, pemeriksaan rutin untuk neo-natus dan bayi. Pelayanan untuk ibu hamil, bayi dan balita juga dilaksanakan di Posyandu setiap bulannya oleh bidan desa. Program penempatan bidan desa di seluruh desa di Indonesia telah dilaksanakan sejak tahun 1988. Jaminan kesehatan juga telah dilaksanakan pada tahun 2004 dan khusus untuk persalinan dilaksanakan Jaminan Persalinan (Jampersal) pada tahun 2011. Program Jampersal telah terintegrasi dalam Jaminan Kesehatan Nasional yang dikoordinasi oleh Badan Penyelenggara Jaminan Sosial (BPJS) pada tahun 2014. Berbagai kebijakan tersebut ternyata belum dapat membuat $A K I$ dan AKB di Indonesia turun secara signifikan (Pardosi et al., 2017).
Salah satu kabupaten di Indonesia yang masih menghadapi masalah kesehatan ibu dan anak adalah Kabupaten Pandeglang, Provinsi Banten. Jumlah kematian ibu di Kabupaten Pandeglang sebanyak 38 kasus pada tahun 2016. Penyebab kematian ibu yang utama adalah karena perdarahan (8 kasus) dan hipertensi dalam kehamilan ( 7 kasus). Jumlah kematian bayi neonatal (usia 0-28 hari) di Kabupaten Pandeglang pada tahun 2016 juga masih cukup tinggi yaitu sebanyak 254 kasus. Kebanyakan penyebab kematian neonatal adalah karena asfiksia (72 kasus) dan BBLR (56 kasus) (Dinkes Kab. Pandeglang, 2016).

Persalinan ditolong oleh tenaga kesehatan di Provinsi Banten pada tahun 2014 baru mencapai $92.39 \%$. Cakupan persalinan ditolong tenaga kesehatan Kabupaten Pandeglang menempati urutan kedua terendah di Provinsi Banten yaitu sebesar $89.60 \%$. Cakupan persalinan oleh tenaga kesehatan di fasilitas kesehatan Kabupaten Pandeglang menempati urutan terendah di Provinsi Banten yaitu 51.35\% (Pusdatin Kemenkes, 2018)

Data Profil Dinas Kesehatan Kabupaten Pandeglang tahun 2016 menunjukkan belum semua persalinan ditolong oleh bidan atau tenaga kesehatan lainnya. Persalinan ditolong oleh tenaga kesehatan sebanyak $72,6 \%$ dan pertolongan persalinan oleh tenaga kesehatan di fasilitas kesehatan sebesar 64\%. Masih rendahnya cakupan persalinan oleh tenaga kesehatan di fasilitas kesehatan dikarenakan masih banyak ibu yang memilih melahirkan dengan ditolong oleh dukun beranak yang dalam bahasa lokal disebut dengan paraji (Dinkes Kab. Pandeglang, 2016)

Dinas Kesehatan Kabupaten Pandeglang telah melaksanakan berbagai upaya untuk mengatasi masalah kesehatan ibu dan anak diantaranya adalah adanya Rumah Tunggu Kelahiran (RTK), adanya kemitraan bidan dengan dukun (paraji), 
sosialisasi persalinan oleh nakes dan tanda-tanda bahaya persalinan dan nifas, Program Perencanaan Persalinan dan Pencegahan Komplikasi (P4K), adanya kerjasama dengan tokoh masyarakat dan tokoh agama dalam upaya mendorong persalinan oleh tenaga kesehatan. Namun berbagai upaya yang telah dilakukan Dinas Kesehatan Kabupaten Pandeglang belum dapat secara maksimal menurunkan jumlah kematian ibu dan bayi (Suharmiati dkk, 2017).

Pusat Humaniora dan Manajemen Kesehatan Badan Litbangkes pada tahun 2017 dan 2018 melaksanakan Riset Intervensi Kesehatan di Kabupaten Pandeglang dalam upaya meningkatkan persalinan di fasilitas pelayanan kesehatan di Kecamatan Cimanggu. Intervensi dilakukan di dua desa yaitu Desa Tugu dan Desa Rancapinang. Paraji adalah sebutan bagi penolong persalinan tradisional. Kokolot adalah sebutan bagi orang yang dituakan pada masyarakat Sunda. Pelatihan dilaksanakan dengan metode sosialisasi tentang kesehatan ibu dan anak kepada paraji dan kokolot. Sebelum pelatihan kepada paraji dan kokolot dilaksanakan dilakukan advokasi terhadap Dinas Kesehatan Kabupaten Pandeglang, Puskesmas Cimanggu dan para pemangku kepentingan dalam lingkup Kecamatan Cimanggu (Suharmiati dkk, 2017).

Tulisan ini bertujuan untuk memberikan gambaran relevansi, efektivitas dan sustainabilitas dari model pemberdayaan paraji dan kokolot dalam upaya meningkatkan persalinan di fasilitas pelayanan kesehatan yang dilaksanakan oleh Pusat Humaniora dan Manajemen Kesehatan Badan Litbangkes di Desa Tugu dan Desa Rancapinang, Kecamatan Cimanggu, Kabupaten Pandeglang pada tahun 2017 dan 2018.

\section{METODE}

Data tulisan ini diperoleh dari penelitian dengan menggunakan pendekatan kualitatif dengan metode Participatory Action Research (PAR). PAR adalah penelitian yang melibatkan orang yang diteliti dengan tujuan untuk mengedukasi dan melakukan aksi agar terjadi perubahan sosial. Metode PAR berpusat pada isu dan kekuatan yang ada di masyarakat tempat lokasi riset dilakukan (Minkler, 2000). Lokasi penelitian terletak di Desa Tugu dan Desa Rancapinang, Kecamatan Cimanggu, Kabupaten Pandeglang.

Teknik pengumpulan data primer yang dilakukan adalah wawancara mendalam, diskusi kelompok terarah (FGD), dan observasi. Wawancara mendalam dilakukan terhadap pihak Dinas Kesehatan Kabupaten Pandeglang dan pihak Puskesmas Cimanggu. FGD dilakukan kepada lintas sektor di Kecamatan Cimanggu serta FGD paraji dan kokolot di Desa Tugu dan Rancapinang. Pengumpulan data sekunder juga dilakukan yaitu data profil Dinas Kesehatan Kabupaten Pandeglang, profil Puskesmas Cimanggu, profil Desa Tugu dan profil Desa Rancapinang.

\section{HASIL DAN PEMBAHASAN}

Gambaran Intervensi Model Pemberdayaan Paraji dan Kokolot sebagai Agent of Change dalam Upaya Meningkatkan Persalinan di Fasilitas Kesehatan

Lokus penelitian ini adalah Desa Tugu dan Desa Rancapinang, Kabupaten Pandeglang. Desa Tugu dipilih menjadi lokasi penelitian karena sebelumnya pada tahun 2015 telah dilaksanakan Riset Etnografi Kesehatan dimana hasilnya menunjukkan bahwa kokolot memiliki peranan besar di dalam masyarakat Desa Tugu. Desa Rancapinang dipilih dengan alasan masih cukup tingginya jumlah persalinan dengan ditolong oleh paraji di desa tersebut. Model intervensi yang dilakukan adalah dengan metode pemberdayaan masyarakat dengan menggunakan agen perubahan. Agen perubahan terdiri dari paraji dan kokolot di Desa Tugu dan Rancapinang. Pelatihan dilaksanakan dengan metode sosialisasi tentang kesehatan ibu dan anak kepada paraji dan kokolot. Sebelum pelatihan kepada paraji dan kokolot dilakukan advokasi terhadap Dinas Kesehatan Kabupaten Pandeglang, Puskesmas Cimanggu dan para pemangku kepentingan dalam lingkup Kecamatan Cimanggu. Tujuan dari advokasi ini untuk merangsang keterlibatan dan interaksi pemangku kepentingan agar bersama-sama bertanggung jawab mengatasi masalah kesehatan ibu dan anak di Kecamatan Cimanggu. 
Pada tahun pertama intervensi yaitu tahun 2017 paraji dan kokolot diberikan pelatihan mengenai tanda-tanda bahaya kehamilan dan pentingnya melahirkan di fasilitas kesehatan. Metode pelatihan yang digunakan adalah dengan metode pemberian materi tatap muka. Mayoritas paraji dan kokolot yang dilatih usianya sudah tua dan tidak bisa membaca dan menulis. Hal ini menyebabkan kurangnya pemahaman paraji dan kokolot terhadap materi pelatihan yang diberikan sehingga perlu dilakukan penyesuaian bentuk dan metode materi pelatihan (Suharmiati dkk, 2017).

Kemudian pada tahun kedua intervensi yaitu tahun 2018 dilakukan pelatihan kembali kepada paraji dan kokolot untuk menyegarkan kembali materi yang sudah diberikan pada tahun 2017. Metode pelatihan yang digunakan pada tahun
2018 adalah dengan menggunakan metode permainan ular tangga yang disertai dengan gambar-gambar. Paraji dan kokolot memiliki peran untuk memotivasi ibu hamil dan keluarganya agar bersedia melahirkan di fasilitas kesehatan dengan ditolong oleh petugas kesehatan. Selain paraji dan kokolot, model intervensi ini juga melibatkan peneliti daerah sebagai pendamping yaitu satu orang berada di Desa Tugu dan satu orang berada di Desa Rancapinang. Peneliti daerah memiliki peran untuk memonitoring apa yang dilakukan paraji dan kokolot sekaligus memberikan motivasi kepada mereka. Peneliti daerah juga memiliki peran untuk menjembatani kerjasama antara paraji, kokolot dengan bidan yang bertugas di Desa Tugu dan Desa Rancapinang (Suharmiati dkk, 2018).

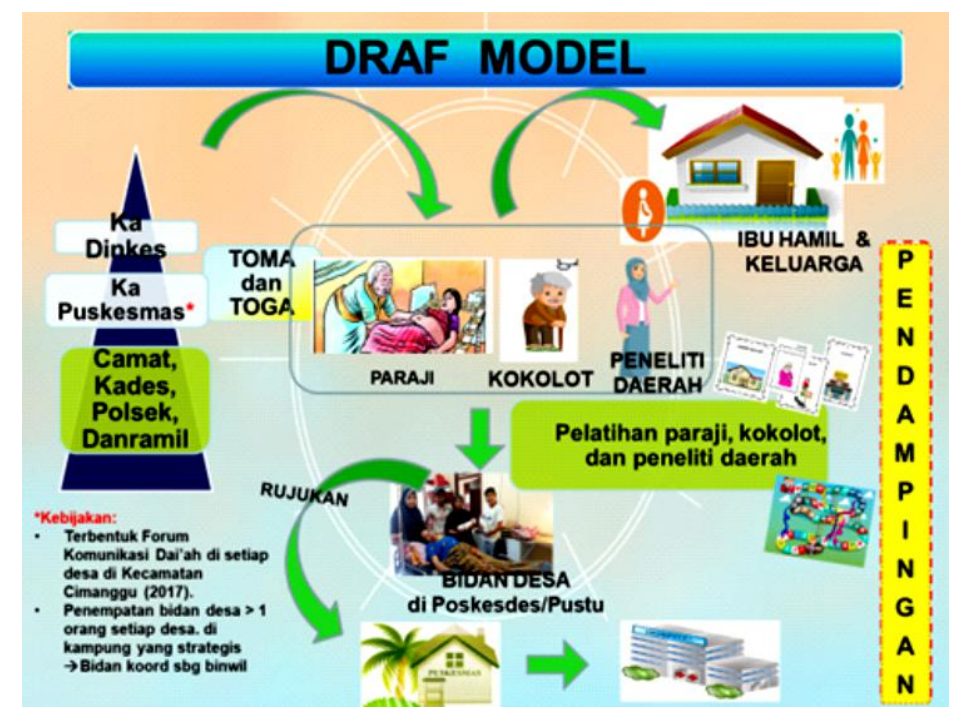

Gambar 1. Draft Model Pemberdayaan Paraji dan Kokolot Sumber : (Suharmiati dkk, 2018)

\section{Relevansi Model Intervensi Pemberdayaan Paraji dan Kokolot}

Relevansi adalah sejauh mana program atau proyek dapat mengatasi masalah yang menjadi prioritas, khususnya pada manfaat dari program terhadap masyarakat. Pertanyaan lain adalah sejauh mana program yang dilakukan sesuai dengan program yang lain di area yang sama (tumpang tindah atau saling melengkapi). Pertanyaan terkait dengan relevansi adalah apakah manfaat dari program juga menyediakan kemudahan terhadap fasilitas, kemampuan membayar atau alasan lainnya. Pertanyaan lain untuk program pembangunan jangka panjang adalah apakah skema program yang asli dapat terus sesuai untuk diterapkan. Pertanyaan lainnya adalah sejauh mana program atau proyek yang dilakukan sesuai dengan program pembangunan lain yang telah dilakukan dalam bidang dan wilayah yang sama (Dale, 2004)

Masalah kesehatan ibu dan anak salah satunya disebabkan masih adanya ibu melahirkan di rumah dengan ditolong oleh penolong persalinan tradisional yaitu dukun atau paraji. Persalinan yang dilakukan tidak di fasilitas pelayanan 
kesehatan dan ditolong oleh paraji dianggap masyarakat merupakan hal yang biasa dan bukan merupakan suatu masalah. Berdasarkan hasil FGD dengan paraji dan kokolot di Desa Tugu, melahirkan dengan ditolong paraji merupakan hal yang biasa dan sudah dipraktekkan turun temurun. Biasanya yang membuat keputusan siapa penolong persalinan adalah keluarga ibu hamil. Persalinan dengan ditolong paraji oleh masyarakat dianggap hal yang biasa karena sudah merupakan bagian dari budaya mereka. Alasan memilih paraji karena mempertahankan tradisi serta dipengaruhi oleh faktor ekonomi atau biaya yang relatif terjangkau. Seperti yang disampaikan oleh ibu "Rh" 40 tahun (Ramadhan et al., 2015)

"soal nyaman teu nyamanya mah mereun kalo pake paraji, kalo orang sini mah soal nyamannya mah dina keuangannya. Kalo sama bidan mah dobel, tapi nayaman mah nyaman aya bidan kalo ada bidan missal kurang aman langsung di bawa kakaler (puskesmas). Nyaman lagi aya dua-duanya, paraji kan langsung selesai lairan di urut, di kasih jampejampe, jadi ngerasa aman nggak di ganggu ama kunti"

Hasil penelitian menunjukkan bahwa penolong persalinan tradisional seperti pengobat tradisional pada umumnya berakar dari budaya lokal. Pelayanan yang diberikan mereka tidak terbatas dan lebih menyeluruh, mereka juga biasanya dapat memahami penderitaan pasien dalam konteks budaya lokal (Saravanan et al., 2010). Masyarakat menganggap pelayanan yang diberikan oleh paraji dianggap lebih menyeluruh apabila dibandingkan dengan pelayanan melahirkan di faskes dengan ditolong oleh bidan. Pelayanan yang berikan paraji dimulai pada saat ibu hamil yaitu dengan cara memijat ibu hamil, pada saaat persalinan hingga bayi berumur 40 hari. Masyarakat juga menganggap paraji dapat memberikan rasa aman pada saat melahirkan karena paraji membacakan doa-doa keselamatan. Doa-doa yang dibacakan paraji dianggap dapat menghilangkan gangguan makhluk halus yang dapat membahayakan persalinan (Ramadhan et al., 2015).

Penelitian dari Kurniawan, dkk (2015) di Desa Cirinten, Kabupaten Lebak, Banten menunjukkan bahwa paraji menjadi penolong persalinan karena masyarakat masih percaya dengan kemampuan paraji. Kepercayaan terhadap paraji telah berlangsung lama dan diwariskan secara turun temurun (Kurniawan et al., 2015). Penelitian lain di Desa Rancacecek juga memperlihatkan peran paraji sebagai penolong persalinan di masyarakat desa tersebut. Paraji dianggap sebagai bidan lokal, biasanya sudah berusia tua dan merupakan orang lokal daerah tersebut. Paraji memperoleh pengetahuannya bukan dari pelatihan formal tetapi dari pengetahuan yang didapat saat mendampingi atau membantu keluarganya yang adalah paraji. Persalinan ditolong oleh penolong persalinan tradisional menurut perspektif kedokteran modern dianggap dapat membahayakan keselamatan ibu dan anak karena penolong persalinan tradisional tidak dapat mengatasi komplikasi persalinan. Persalinan dengan ditolong penolong persalinan tradisional juga dapat membahayakan kesehatan bayi apabila menggunakan bambu untuk memotong tali pusat karena dapat menyebabkan terjadinya infeksi (Ambaretnani, 2012)

Model intervensi pemberdayaan paraji dan kokolot yang dilaksanakan di Desa Tugu dan Desa Rancapinang Kokolot (orang yang dituakan) dipilih sebagai agen perubahan yang berperan untuk memberikan motivasi kepada ibu hamil dan keluarganya agar mau melahirkan di fasilitas kesehatan. Pemilihan kokolot sebagai agen perubahan cukup relevan karena kokolot memiliki peran dalam pengambilan keputusan di Desa Tugu. Pengambilan keputusan persalinan di desa Tugu sangat dipengaruhi oleh kolot (orang tua) (Ramadhan et al., 2015).

Pemilihan kokolot sebagai agen perubahan juga didukung dari hasil Penelitian dari Suradisastra dan Priyanto mengenai "Pemberdayaan Posisi dan Peran Tokoh Tradisional dalam Upaya Pengembangan Ternak" di Kampung Domba Kabupaten Pandeglang memperlihatkan bahwa peran tokoh pemimpin di desa baik pemimpin formal atau informal cukup mempengaruhi keberhasilan keberlanjutan kegiatan pemberdayaan masyarakat dalam pengembangan ternak. Tokoh pemimpin informal terutama yang sudah berusia tua disebut dengan kokolot (Suradisastra \& Priyanto, 2011).

Kokolot memiliki peran dalam hal persalinan dengan cara memberikan air putih yang sudah didoakan sehingga memberikan rasa aman kepada ibu bersalin. Hasil FGD lintas sektor Kecamatan Cimanggu menunjukkan tradisi memanggil kokolot untuk memberikan air putih yang telah didoakan kepada ibu yang melahirkan terkait dengan kepercayaan masyarakat bahwa orang yang melahirkan rentan diganggu oleh makhluk ghaib. Oleh karena itu untuk memberikan rasa aman dari gangguan makhluk ghaib maka dipanggillah kokolot yang bisa memberikan doadoa atau dalam istilah lokal disebut dengan "selusuh". 
Itu yang apa namanya dikasih airnya diisi doa terus kemudian ibunya berangkat ke paraji dengan membaca selusuh itu ya pak ya dengan air itu (Abah Sali, FGD Desa Tugu)

kalau dikampung itu kan biasanya kalau melahirkan itu identik dengan yang ghaib-ghaib gitu, yang berbau mistis ya bu ya. Kalau dikampung-kampung itu kalau melahirkan itu biasanya ada kuntilanak lah atau apa lah kesurupan atau gimana jadi diberikan jampe ah dikampung itu sifatnya yang segera mendatangkan yang sifatnya yang seperti itu bu. (Hasil FGD Lintas Sektor Kecamatan Cimanggu)

Alasan masyarakat memilih paraji sebagai penolong persalinan dan kokolot berdasarkan penjabaran di atas dapat diklasifikasikan ke dalam tiga kategori utama yaitu kepercayaan dan lokal tradisi, faktor ekonomi, dan kebutuhan yang dirasakan. Faktor-faktor tersebut sejalan dengan penelitian yang dilakukan Titaley, dkk yang menggolongkannya dalam lima kategori yaitu ekonomi dan pragmatis, kepercayaan dan tradisi, kebutuhan, akses ke layanan dan persepsi masyarakat terhadap pengetahuan dan keterampilan tenaga kesehatan di fasilitas kesehatan. penelitian ini menggunakan paraji dan kokolot sebagai agen perubahan memiliki dasar yang cukup relevan. Agen perubahan tersebut dapat dengan mudah mempengaruhi masyarakat untuk memiliki pemahaman yang lebih baik tentang pentingnya melakukan persalinan di fasilitas kesehatan (Titaley et al., 2010).

Hasil penelitian dari Anke Niehof tentang "Penolong persalinan tradisional dan permasalahan kematian ibu di Indonesia" menunjukkan bahwa perempuan yang tinggal di wilayah pedesaan di Kota Serang banyak yang lebih memilih melahirkan ditolong paraji dibanding ditolong bidan atau dokter. Hal ini dikarenakan melahirkan ditolong paraji sudah tradisi dan pelayanannya lebih lengkap dibandingkan pelayanan persalinan dengan ditolong bidan desa. Pelayanan paraji lebih lengkap dari mulai kehamilan seperti memberi pijatan pada ibu hamil, pada saat persalinan sampai bayi sudah lahir paraji masih memberikan perawatan kepada ibu dan bayi (Niehof, 2014).

\section{Efektivitas Model Intervensi}

Efektivitas adalah apakah sejauh mana perubahan yang diharapkan baik perubahan dalam waktu singkat atau tujuan dari program dapat tercapai (impact) (Dale, 2004). Tujuan dari model intervensi Pemberdayaan Paraji dan Kokolot di Desa Tugu dan Desa Rancapinang adalah untuk meningkatkan persalinan di fasilitas kesehatan. Berikut ini adalah grafik cakupan K1, K4 dan persalinan oleh tenaga kesehatan di Desa Tugu dan Desa Rancapinang pada tahun 2016 2018.

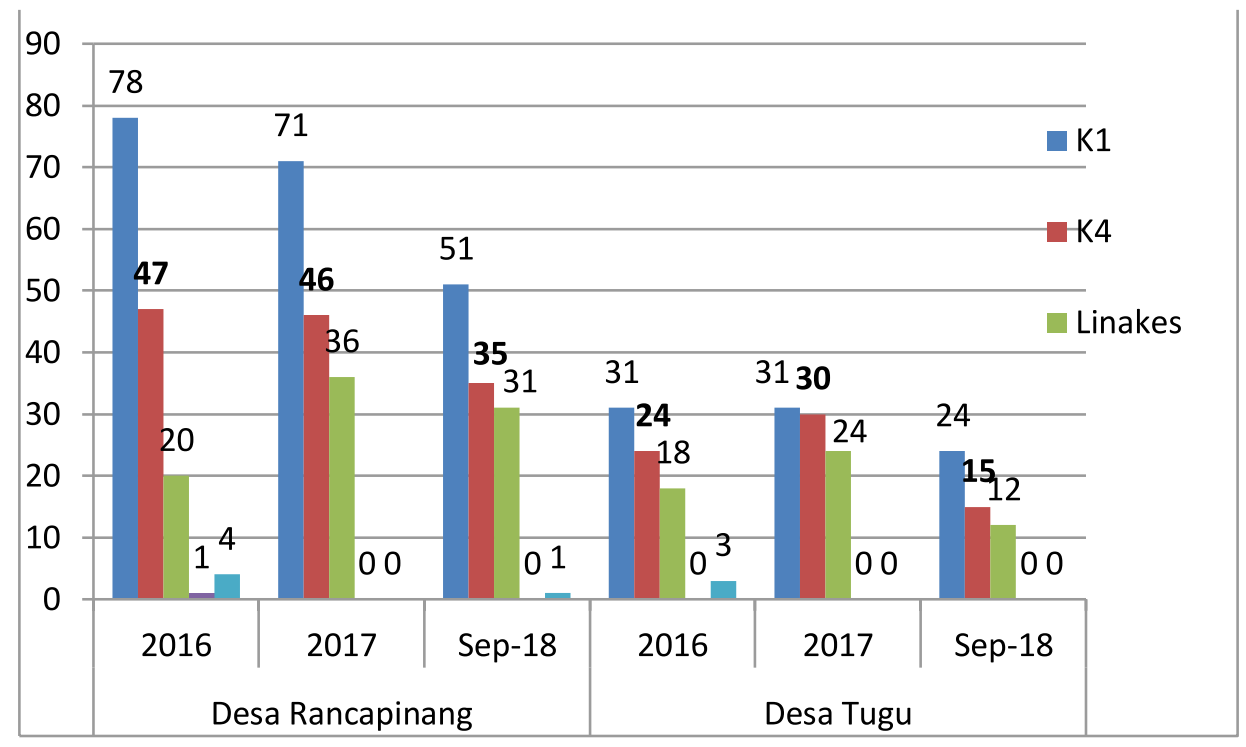

Gambar 2. K1, K4, Persalinan Linakes, Kematian Ibu dan kematian Bayi

Desa Rancapinang dan Desa Tugu, Tahun 2016, 2017 dan 2018 (Sept)

Sumber: PWS KIA Puskesmas Cimanggu 2016, 2017, 2018 (Sept) dalam Suharmiati dkk, 2018) 
Berdasarkan grafik persalinan Linakes di Desa Tugu dan Rancapinang sebelum intervensi dilakukan yaitu tahun 2016 jumlah Linakes di Desa Tugu adalah 20 kasus. Pada tahun 2017 meningkat menjadi 36 kasus dan sampai bulan September 2018 tercatat 31 kasus. Hasil tersebut memperlihatkan bahwa ada peningkatan jumlah persalinan di fasilitas kesehatan sebelum dan sesudah model intervensi pemberdayaan paraji dan kokolot dilaksanakan di Desa Tugu. Berbeda dengan Desa Tugu, di Desa Rancapinang sebelum dan sesudah intervensi jumlah persalinan di fasilitas kesehatan hanya meningkat sedikit dari 18 kasus pada tahun 2016 menjadi 24 kasus pada tahun 2017 dan menurun menjadi 12 kasus sampai akhir September tahun 2018.

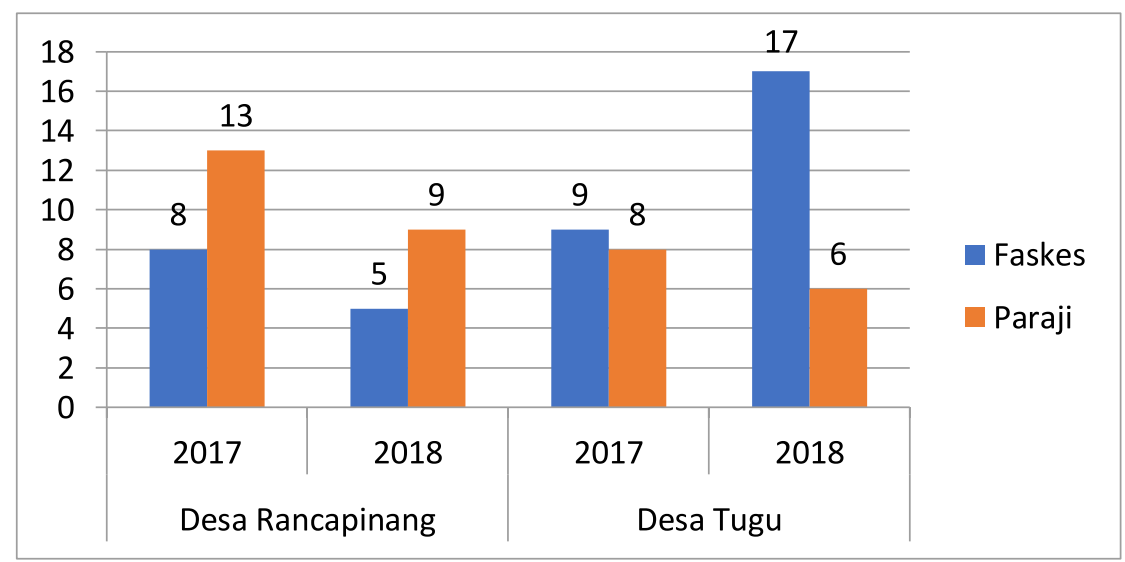

\section{Gambar 3. Tempat melahirkan ibu bersalin di Desa Rancapinang dan Desa Tugu tahun 2017 dan 2018 Sumber: (Suharmiati dkk, 2018)}

Gambar 3 memperlihatkan grafik tempat ibu bersalin di Desa Tugu dan Rancapinang pada tahun 2017 dan 2018. Grafik tersebut memperlihatkan bahwa pada tahun pertama intervensi yaitu tahun 2017 jumlah ibu bersalin yang melahirkan di fasilitas kesehatan di Desa Tugu lebih banyak dibandingkan di Desa Rancapinang. Hal ini juga terjadi pada tahun kedua intervensi yaitu tahun 2018, jumlah ibu bersalin yang melahirkan di paraji lebih banyak di Desa Rancapinang dibandingkan di Desa Tugu.

Berdasarkan data tersebut dapat disimpulkan efektivitas model pemberdayaan paraji dan kokolot di Desa Tugu lebih baik dibandingkan dengan Desa Rancapinang. Ada beberapa faktor yang menyebabkan terjadinya perbedaan ini yaitu: Pertama, dari segi luas wilayah, Desa Rancapinang memiliki wilayah yang lebih luas dari Desa Tugu Luas Desa Rancapinang $4.500 \mathrm{~km}^{2}$ dengan jumlah penduduk 4.250 jiwa yang tersebar di enam wilayah RW dan 28 RT. Desa Tugu memiliki luas 700 hektar dengan jumlah penduduk 1.560 jiwa yang tersebar di 4 wilayah RW dan 15 RT. Lokasi Desa Rancapinang juga lebih terpencil dibanding Desa Tugu. Desa Rancapinang merupakan desa paling ujung di Kecamatan Cimanggu yang letaknya berbatasan dengan Samudera Hindia. Jarak tempuh dari Kecamatan Cimanggu ke Desa Rancapinang sekitar dua jam dengan menggunakan kendaraan roda empat dengan akses jalan yang rusak dan berlubang. Sedangkan jarak tempuh dari Kecamatan Cimanggu ke Desa Tugu lebih dekat sekitar satu jam.

Kedua, paraji dan kokolot di Desa Tugu lebih banyak yang sudah bekerjasama dengan bidan dibandingkan dengan paraji dan kokolot yang ada di Desa Rancapinang. Hampir semua paraji di Desa Tugu sudah bermitra dengan bidan dan tidak lagi menolong persalinan sendiri. Hanya ada satu orang paraji yang belum bermitra dikarenakan paraji tersebut dianggap memiliki ilmu ghaib yang cukup tinggi sehingga sulit untuk melakukan pendekatan terhadap paraji tersebut. Dari 10 orang kokolot yang menjadi agen perubahan di Desa Rancapinang hanya ada empat orang yang aktif memberikan pendampingan kepada ibu hamil. Paraji di Desa Rancapinang masih ada yang belum bermitra dengan bidan dan masih menolong persalinan sendiri.

\section{Sustainabilitas Model Intervensi}

Sustainabilitas adalah pemeliharaan dari pencapaian positif yang diakibatkan oleh program yang masih terjadi setelah implementasi program berakhir. Evaluasi dilakukan dengan melihat apakah skema dari program dapat terus berlanjut (sustain) 
walaupun program telah berakhir. Sustainabilitas terkait dengan semua level dari kerangka cara dan tujuan yang dilakukan. Hal ini terkait dengan apakah program pembangunan ini akan dilanjutkan atau berhenti setelah intervensi selesai dilakukan oleh organisasi yang sama atau organisasi yang lain (Dale, 2004).

Program pengembangan masyarakat dalam bidang kesehatan dapat terus berlanjut dan diterima oleh masyarakat apabila program tersebut terintegrasi dengan program pengembangan masyarakat di bidang lainnya. Untuk dapat terus berlanjut program pengembangan masyarakat kesehatan juga harus berasal dari masyarakat, masyarakat merasa memiliki program tersebut dan program tersebut juga melekat pada masyarakat (Rifkin, 2009).

Model intervensi pemberdayaan paraji dan kokolot yang dilaksanakan di Desa Tugu dan Desa Rancapinang belum terintegrasi dengan program pengembangan masyarakat di bidang lainnya. Sustainabilitas model intervensi ini diragukan karena usulan model ini bukan berasal dari masyarakat Desa Tugu dan Rancapinang tetapi dari pihak luar yaitu peneliti dari Badan Litbangkes. Hal ini membuat kurangnya rasa kepemilikan masyarakat terhadap program ini. Selain itu ketika model intervensi ini selesai dilaksanakan selama dua tahun di Desa Tugu dan Rancapinang dari pihak Dinas Kesehatan Kabupaten Pandeglang belum memiliki rencana untuk melanjutkan model intervensi ini. Pemerintah daerah setempat seharusnya membuat suatu kebijakan yang dapat membuat program pengembangan masyarakat yang sudah ada dapat mengimplementasikan model pemberdayaan paraji dan kokolot. Adanya kebijakan ini dapat mebuat semua pihak dapat terlibat dalam upaya peningkatan persalinan di fasilitas kesehatan. Penolong persalinan tradisional telah dilatih dan terintegrasi dalam sistem kesehatan mereka tidak akan merasa terancam dengan kehadiran bidan, mereka akan dipandang sebagai pemangku kepentingan dalam upaya meningkatkan kesehatan ibu. Penolong tradisional akan bertindak sebagai konselor yang sangat membantu dalam memberikan kenyamanan kepada ibu yang akan bersalin di pedesaaan atau di daerah terpencil walaupun pada saat tengah malam (Harrison, 2011).

Pada kasus model intervensi yang dilaksanakan di Desa Tugu dan Rancapinang walaupun paraji telah dilatih tetapi pada kenyataannya tidak semua paraji mau bekerjasama dengan bidan dan tidak menolong persalinan lagi. Hal ini terjadi terutama pada paraji yang tinggal di Desa Rancapinang walaupun mereka sudah dilatih menjadi agen perubahan beberapa orang diantaranya masih menolong persalinan. Kemitraan antara paraji dengan bidan di Desa Rancapinang belum berjalan dengan baik. Model intervensi yang dilaksanakan belum terintegrasi ke dalam sistem kesehatan yang ada dalam hal ini sistem kesehatan yang ada di Puskesmas Cimanggu.

Salah satu contoh program kemitraan dan bidan yang telah berjalan dengan baik dapat dilihat dari hasil penelitian dari Panuntun et al, 2019 yang menunjukkan bahwa program kemitraan antara bidan dengan dukun di Kabupaten Klaten, Jawa Tengah dapat berjalan dengan baik karena mereka saling melengkapi dan saling memperkuat satu sama lain. Kemitraan bidan dengan dukun ini juga telah didukung oleh regulasi dari pemerintah dari setempat (Panuntun et al., 2019).

Selain itu komitmen dari Dinas Kesehatan Kabupaten Pandeglang sebagai pemerintah daerah setempat untuk melanjutkan model intervensi ini juga belum terlihat. Padahal pemerintah daerah memiliki peran penting dalam mengatasi masalah kesehatan ibu dan anak. Studi dari Pardosi, dkk menjelaskan bahwa perlunya tindakan lebih jauh dari pemerintah daerah untuk meningkatkan kualitas pelayanan kesehatan primer di pedesaan. Pemerintah daerah juga perlu meningkatkan distribusi bidan di pedesaan dan daerah terpencil dan meningkatkan keterlibatan pemimpin-pemimpin lokal di setiap wilayah dalam program kesehatan (Pardosi et al., 2017).

Penelitian dari Annemijn E.C. Sondaal et al mengenai keberlanjutan program intervensi kesehatan ibu dan anak berbasis masyarakat di Nepal menemukan beberapa faktor yang mempengaruhi keberlanjutan program tersebut yaitu kepentingan lokal, peserta program memperoleh pengetahuan, aktivitas yang terintegrasi, dukungan finansial (Sondaal et al., 2019). Implementasi model pemberdayaan paraji dan kokolot di Desa Tugu dan Rancapinang sudah sesuai dengan kepentingan lokal karena kedua desa tersebut menghadapi masalah masih adanya persalinan yang tidak dilakukan di fasilitas kesehatan. Agen perubahan juga memperoleh pengetahuan tentang kesehatan ibu dan anak dengan mengikuti kegiatan dalam model intervensi ini. Tetapi model ini belum termasuk aktivitas yang terintegrasi karena ketika dana program intervensi ini berakhir maka kegiatan juga terhenti. Dukungan dana dari organisasi masyarakat setempat juga belum ada sehingga model ini diragukan keberlanjutannya. 


\section{KESIMPULAN DAN SARAN}

\section{Kesimpulan}

Model intervensi pemberdayaan paraji dan kokolot dalam meningkatkan persalinan di fasilitas kesehatan cukup relevan untuk dilaksanakan di Desa Tugu dan Desa Rancapinang karena kedua desa tersebut masih menghadapi masalah belum semua ibu hamil melahirkan di fasilitas kesehatan. lbu hamil masih ada yang melahirkan di rumah dengan ditolong oleh paraji. Pemilihan paraji dan kokolot sebagai agen perubahan dalam model ini juga cukup relevan karena paraji dan kokolot memiliki peranan yang cukup penting di dalam budaya masyarakat Desa Tugu dan Rancapinang. Paraji dan kokolot sebagai agen perubahan dapat dimobilisasi dan diberdayakan untuk bekerjasama dengan tenaga kesehatan dalam mengatasi masalah kesehatan ibu dan anak khususnya dalam meningkatkan upaya mencegah kematian ibu dan anak.

Dari segi efektivitas, implementasi model ini lebih efektif dilaksanakan di Desa Tugu dibandingkan dengan di Desa Rancapinang dikarenakan karakteristik wilayah Desa rancapinang yang berbeda dengan Desa Tugu. Tetapi keberlanjutan atau sustainabilitas model intervensi ini masih diragukan karena model ini belum terintegrasi dengan sistem pelayanan kesehatan di daerah tersebut. Pemerintah daerah setempat juga belum menunjukkan komitmen untuk melanjutkan model intervensi ini.

\section{Saran}

Model intervensi pemberdayaan paraji dan kokolot perlu dimodifikasi sesuai dengan karakteristik sosial dan budaya masyarakat. Untuk meningkatkan efektivitas model ini maka perlu adanya kemitraan yang kuat antara paraji, kokolot sebagai agen perubahan, bidan desa dan fasilitator lokal. Kemitraan antara paraji dan kokolot harus bersifat setara dalam artian baik paraji atau bidan adalah mitra yang saling bekerja sama dan saling melengkapi untuk mencapai tujuan yang sama yaitu meningkatkan persalinan di fasilitas kesehatan.

Selain itu diperlukan juga pendampingan yang intensif dari pendamping lokal dan montoring yang berkala dari pihak Puskesmas atau Dinas Kesehatan. Agar sustainabilitas model ini dapat berjalan maka diperlukan advokasi kepada pemangku kepentingan lokal. Advokasi diperlukan agar model ini dapat terintegrasi dengan sistem pelayanan kesehatan di daerah tersebut. Rasa kepemilikan terhadap model ini juga perlu ditumbuhkan kepada masyarakat dan pemangku kepentingan lokal agar mereka dapat berpartisipasi penuh dalam model ini.

\section{UCAPAN TERIMA KASIH}

Penulis mengucapkan terimakasih kepada Kepala Puslitbang Humaniora dan Manajemen Kesehatan, Kepala Bidang Humaniora Kesehatan, Kepala Bidang Sosial dan Budaya serta Dinas Kesehatan Kabupaten Pandeglang, Puskesmas Cimanggu, Bidan Desa Tugu, Bidan Desa Rancapinang, Peneliti daerah, paraji dan kokolot Desa Tugu dan Rancapinang serta kepada semua pihak yang terlibat dalam penelitian ini.

\section{KONTRIBUSI PENULIS}

Sri Handayani dan Suharmiati adalah kontributor utama dala artikel, dengan tugas Sri Handayani melakukan pengembangan ide utama, mengembangkan pendahuluan, dan metodologi serta melakukan analisis data dan menulis hasil. Suharmiati mengembangkan metode dan diskusi serta mensitesa kesimpulan dan saran. Sedangkan Karlina dan Yurika adalah kontributor anggota yang berkontribusi pada pemeriksaan kelengkapan naskah, memberi masukan pada metodologi, kerangka pikir dan diskusi.

\section{DAFTAR PUSTAKA}

Ambaretnani, P. (2012). Paraji and Bidan in Rancaekek: Integrated Medicine for Advanced Partnerships among Traditional Birth Attendants and Community Midwives in the Sunda Region of West Java, Indonesia. Doctoral Thesis, Leiden University. https://doi.org/9789085709770

Badan Pusat Statistik. (2017). Survei Demografi Kesehatan Indonesia. Bkkbn, 1-606.

Dale, R. (2004). Evaluating Development Programmes and Projects (Vol. 3, Issue 2). New Delhi : Sage Publication Ltd.

Dinkes Kab. Pandeglang. (2016). Profil Kesehatan Kabupaten Pandeglang Tahun 2016. Pandeglang : Dinas Kesehatan Kab. Pandeglang.

Harrison, K. A. (2011). Are traditional birth attendants good for improving maternal and perinatal health? No. BMJ (Clinical Research Ed.), 342(7811), 1340-1341. https://doi.org/10.1136/bmj.d3308

Kurniawan, A., Handayani, L., \& Suharmiati. (2015). Sinergi Bidan dan Paraji: Mencari Sisi Kemajuan Dalam Sistem Pelayanan Kesehatan Ibu dan Anak. Buletin Penelitian Sistem Kesehatan, 18(3), 229-238. https://media.neliti.com/media/publications/20948-IDsynergy-of-midwives-and-paraji-finding-the-plurality- 
side-in-the-maternal-and-ch.pdf

Minkler, M. (2000). Using participatory action research to build healthy communities. Public Health Reports, 115(2-3), 191-197. https://doi.org/10.1093/phr/115. 2. 191

Niehof, A. (2014). Traditional birth attendants and the problem of maternal mortality in Indonesia. In Pacific Affairs (Vol. 87, Issue 4, pp. 693-713). https://doi.org/ $10.5509 / 2014874693$

Panuntun, S., Karsidi, R., Murti, B., \& Akhyar. (2019). The Role of Midwives and Traditional Birth Attendant Partnership Program in Empowering Traditional Birth Attendant to Improve Maternal Health in Klaten, Central Java. Journal of Maternal and Child Health, 4(4), 279-286. https://doi.org/10.26911/thejmch. 2019.04.04.07

Pardosi, J. F., Parr, N., \& Muhidin, S. (2017). Local government and community leaders' perspectives on child health and mortality and inequity issues in rural eastern Indonesia. Journal of Biosocial Science, 49(1), 123-146. https://doi.org/10.1017/ S00219320 16000134

Pusdatin Kemenkes. (2018). Profil Kesehatan Indonesia 2017.

Ramadhan, A., Vitriyani, E., \& Angkasawati, T. J. (2015). Belenggu Kokolot: Pada Ibu Hamil dan Melahirkan Etnik Sunda, Kabupaten Pandeglang. Surabaya : UNESA University Press.

Rifkin, S. B. (2009). Lessons from community participation in health programmes: a review of the post Alma-Ata experience. International Health, 1(1), 31-36. https://doi.org/10.1016/j.inhe.2009.02.001
Saravanan, S., Turrell, G., Johnson, H., \& Fraser, J. (2010). Birthing practices of traditional birth attendants in South Asia in the context of training programmes. Journal of Health Management, 12(2), 93-121. https://doi.org/10.1177/097206341001200201

Sondaal, A. E. C., Tumbahangphe, K. M., Neupane, R., Manandhar, D. S., Costello, A., \& Morrison, J. (2019). Sustainability of community-based women's groups: Reflections from a participatory intervention for newborn and maternal health in Nepal. Community Development Journal, 54(4), 731-749. https://doi.org/10.1093/cdj/bsy017

Suharmiati dkk. (2017). Laporan Penelitian Riset Intervensi Kesehatan Kabupaten Pandeglang 2017. Jakarta : Badan Litbang Kemenkes RI.

Suharmiati dkk. (2018). Laporan Penelitian Riset Intervensi Kesehatan Kabupaten Pandeglang 2018. Jakarta : Badan Litbang Kemenkes RI.

Suradisastra, K., \& Priyanto, D. (2011). Pemberdayaan Posisi Dan Peran Tokoh Tradisional Dalam Upaya Pengembangan Ternak Di Provinsi Banten. Wartazoa, 21, 51-59. http://peternakan.litbang.deptan.go.id/ fullteks/wartazoa/wazo212-1.pdf

Titaley Christiana, R., Hunter Cynthia, L., Dibley Michael, J., \& Peter, H. (2010). Why do some women still prefer traditional birth attendants and home delivery?: a qualitative study on delivery care services in West Java Province, Indonesia. BMC Pregnancy and Childbirth, 10, 43. http://ovidsp.ovid.com/ovidweb.cgi? $\mathrm{T}=\mathrm{JS} \& \mathrm{PAGE}=$ reference \&D$=$ medl $\& N E W S=\mathrm{N} \& A N=20$ 701762 